\title{
Mutagenic Efficiency of Lower Doses of Gamma rays in Black Cumin (Nigella sativa L.)
}

\author{
Giriesh Kumar* and Priyanka Gupta** \\ Plant Genetics Laboratory, Department of Botany, University of Allahabad, Allahabad-211002, India
}

Received August 6, 2007; accepted October 19, 2007

\begin{abstract}
Summary The seeds of Nigella sativa were treated with 50, 100, 150, 200, 250, 300 Gy doses of gamma rays. A hexapetalous mutant was observed at $100 \mathrm{~Gy}$ dose in $\mathrm{M}_{1}$ generation. It was found to have increased seed weight and seed number as compared to the control plants. The chromosomal abnormalities at $100 \mathrm{~Gy}$ dose were also at the optimum level (17.10\%). Therefore, this dose can be suggested to be beneficial for mutagenesis in plants.
\end{abstract}

Key words Nigella sativa, Gamma rays, Hexapetalous mutant, 100 Gy dose, Seed weight.

Nigella sativa L. (black cumin) is an important spice of commerce and has immense therapeutic use (Pruthi 1998). It belongs to family Ranunculaceae. The plant species is also a good material for cytological studies (Kumar and Nizam 1978) as it has relatively low number of chromosomes $(2 n=12)$ of suitable size and good stainability (Bhattacharya 1958).

Induced chromosomal variations are valuable cytogenetical tools for gene identification, isolation and mapping. Chromosomal variations have been induced by chemical agents (Kumar and Singh 2003), pesticides (Epstein and Legator 1971), heavy metals (Kumar and Rai 2007) and mainly by means of gamma radiation (Ahmad 1993, Vizir et al. 1994, Gecheff 1996, Alvarez et al. 1997, Riera Lizarazu et al. 2000).

Further, the cytological abnormalities during meiosis have also been regarded as one of the dependable parameters for estimating mutagenic sensitivity of a species. In the present study gamma rays have been used to assess its mutagenic efficiency in Nigella sativa and also to determine whether any specific dose can prove to be beneficial for the plant.

\section{Material and methods}

Seeds of Nigella sativa var Azad were obtained from Chandra Shekhar Azad University of Agriculture and Technology, Kanpur. The seeds were exposed to different doses of gamma rays viz. $50,100,150,200,250$ and 300 Gy from $\mathrm{Co}^{60}$ source at National Botanical Research Institute, Lucknow. After the treatment, these seeds were pre-soaked for $12 \mathrm{~h}$ and sown in experimental pots.

For meiotic studies, young floral buds were fixed in Carnoy's fixative $(3: 1)$ for $24 \mathrm{~h}$ and then transferred to $70 \%$ ethyl alcohol. Slides were then prepared by squash method using $2 \%$ acetocarmine.

\section{Results}

Significant morphogenetic variations were observed at different treatment doses. The various morphological parameters and meiotic anomalies have been tabulated in Table 1 and Table 2, re-

*Corresponding author, e-mail:*kumar_girjesh@yahoo.com,** priyanka2302@yahoo.com 

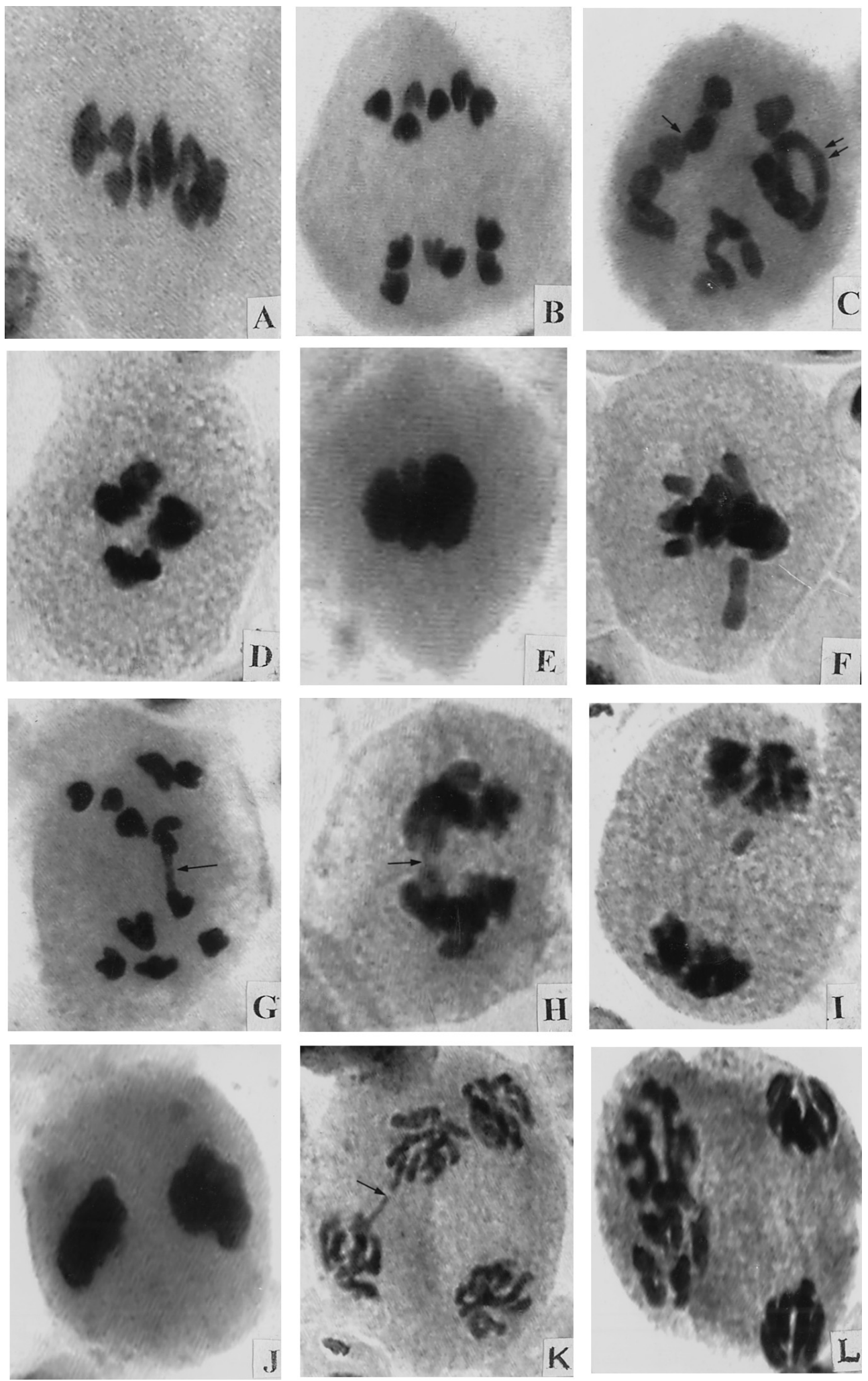
Table 1. Effect of various doses of gamma rays on different morphological parameters

\begin{tabular}{lrrrrrrr}
\hline \hline \multicolumn{1}{c}{ Plant Character } & \multicolumn{1}{c}{ Control } & \multicolumn{2}{c}{ 50 Gy } & \multirow{2}{*}{$100 \mathrm{~Gy}$} & \multirow{2}{*}{$150 \mathrm{~Gy}$} & \multirow{2}{*}{$200 \mathrm{~Gy}$} & \multicolumn{2}{c}{$250 \mathrm{~Gy}$} & \multirow{2}{*}{$300 \mathrm{~Gy}$} \\
\hline Germination (\%) & $98.2 \pm 0.44$ & $91.6 \pm 0.36$ & $86 \pm 0.54$ & $78.2 \pm 0.64$ & $70.3 \pm 0.43$ & $62.4 \pm 0.32$ & $54.4 \pm 0.23$ \\
Survival (\%) & $96.0 \pm 0.35$ & $88.4 \pm 0.63$ & $74.6 \pm 0.53$ & $65.5 \pm 0.72$ & $58.3 \pm 0.62$ & $50.2 \pm 0.38$ & $42.4 \pm 0.26$ \\
Av. plant height (cm) & $54.86 \pm 0.45$ & $53.16 \pm 0.76$ & $48.92 \pm 0.51$ & $46.1 \pm 0.31$ & $42.38 \pm 0.43$ & $38.12 \pm 0.75$ & $36.84 \pm 0.29$ \\
Av. Stem Dia (cm) & $3.96 \pm 0.23$ & $3.8 \pm 0.25$ & $3.69 \pm 0.25$ & $3.64 \pm 0.17$ & $3.02 \pm 0.21$ & $2.46 \pm 0.29$ & $2.18 \pm 0.32$ \\
No. of nodes & $15.4 \pm 0.23$ & $14.6 \pm 0.34$ & $12.6 \pm 0.52$ & $10.4 \pm 0.78$ & $8.6 \pm 0.78$ & $6.4 \pm 0.36$ & $4.3 \pm 0.51$ \\
Days to flowering & $75.2 \pm 0.52$ & $80.0 \pm 0.62$ & $84.5 \pm 0.78$ & $88.2 \pm 0.86$ & $92.6 \pm 0.54$ & $94.0 \pm 0.66$ & $98.8 \pm 0.72$ \\
Days to maturity & $102 \pm 1.00$ & $105.2 \pm 1.35$ & $109.0 \pm 0.89$ & $112.3 \pm 0.78$ & $115.6 \pm 0.92$ & $117.3 \pm 1.13$ & $121.5 \pm 0.86$ \\
100 seed weight (gm) & $9.65 \pm 0.21$ & $9.60 \pm 0.32$ & $9.52 \pm 0.54$ & $9.44 \pm 0.26$ & $9.35 \pm 0.52$ & $9.20 \pm 0.36$ & $9.14 \pm 0.42$ \\
Pollen fertility (\%) & $98.0 \pm 0.34$ & $92.60 \pm 0.23$ & $86.43 \pm 0.64$ & $78.74 \pm 0.45$ & $70.50 \pm 0.72$ & $62.40 \pm 0.52$ & $59.76 \pm 0.37$
\end{tabular}

Table 2. Different cytological abnormalities at various doses of gamma irradiation in Nigella sativa

\begin{tabular}{|c|c|c|c|c|c|c|c|c|c|c|c|c|}
\hline \multirow{2}{*}{ Doses } & \multirow{2}{*}{$\begin{array}{c}\text { Total } \\
\text { No of PMCs } \\
\text { studied }\end{array}$} & \multicolumn{9}{|c|}{ Types of Abnormalities (\%) } & \multirow{2}{*}{$\begin{array}{l}\text { T.Ab } \\
(\%)\end{array}$} & \multirow{2}{*}{$\begin{array}{c}\text { Chiasma } \\
\text { frequency/ } \\
\text { PMC }\end{array}$} \\
\hline & & St & $\mathrm{Mv}$ & $\mathrm{Br}$ & N.S & Mic & $\mathrm{Lg}$ & $\mathrm{Sa}$ & Un & $\mathrm{Pm}$ & & \\
\hline Control & 260 & 2.99 & - & - & - & - & - & - & - & 0.63 & 3.62 & $3.2 \pm 0.4$ \\
\hline $50 \mathrm{~Gy}$ & 540 & 3.21 & 1.32 & 0.24 & - & - & 1.32 & 0.54 & - & 1.14 & 8.77 & $4.5 \pm 0.2$ \\
\hline $100 \mathrm{~Gy}$ & 338 & 5.71 & 3.67 & 1.92 & 0.76 & - & 1.62 & 0.62 & - & 2.80 & 17.10 & $5.6 \pm 0.3$ \\
\hline $150 \mathrm{~Gy}$ & 560 & 8.87 & 5.17 & 2.49 & 0.84 & - & 1.75 & 0.77 & - & 3.97 & 23.48 & $7.8 \pm 0.3$ \\
\hline 200 Gy & 776 & 9.16 & 6.22 & 2.86 & 1.12 & 0.56 & 2.46 & 1.55 & 1.34 & 4.80 & 30.07 & $8.7 \pm 0.2$ \\
\hline $250 \mathrm{~Gy}$ & 352 & 11.86 & 6.76 & 3.86 & 1.66 & 0.67 & 3.30 & 1.72 & 1.92 & 5.68 & 36.43 & $9.3 \pm 0.3$ \\
\hline $300 \mathrm{~Gy}$ & 476 & 12.52 & 7.38 & 4.12 & 1.74 & 0.84 & 3.75 & 2.15 & 2.04 & 7.38 & 41.68 & $9.6 \pm 0.3$ \\
\hline
\end{tabular}

Abbreviations: T.Ab \%: Total abnormality percentage, St-Stickiness, Mv-Multivalent, Br-Bridge, N.S-Non-synchronous division, Mic-Micronuclei, Lg-Laggard, Sa-Secondary association, Un-Unorientation, Pm-Precocious movement.

spectively. In the control set, germination was recorded as $92.6 \%$ while in irradiated sets it decreased from $90 \%$ to $58.3 \%$ along with increasing treatment doses. Survival percentage also decreased from $88.4 \%$ to $42.4 \%$ along with the increasing doses of gamma rays from $50-300 \mathrm{~Gy}$.

Other morphological parameters also showed considerable variations (Table 1). The analysis of morphological parameters revealed that the plant height in control sets was found to be $54.86 \pm 0.45 \mathrm{~cm}$ while it decreased from $53.16 \pm 0.76$ to $36.84 \pm 0.29 \mathrm{~cm}$ at different doses of gamma irradiated sets. Stem diameter was recorded to be $3.96 \pm 0.23 \mathrm{~cm}$ in control set while in gamma-irradiated sets it decreased from $3.8 \pm 0.25$ to $2.18 \pm 0.32 \mathrm{~cm}$. Similarly, the number of nodes in control sets was $15.4 \pm 0.23$ while it decreased from $14.6 \pm 0.34$ to $4.3 \pm 0.64$ in gamma irradiated sets .The other morphological parameters like days to flowering and days to maturity increased while the seed weight and pollen fertility showed a decreasing trend in the treatment doses as compared to control.

Cytological analysis (Figs. 1A-L) revealed normal meiosis in control plants $(n=6)$ and 6 bivalents were observed at metaphase-I (Fig. 1A). Normal anaphasic separation (6:6) was observed at Anaphase-I (Fig. 1B). However, in the gamma-irradiated sets, PMCs showed various chromosomal disturbances during meiosis. The frequency of meiotic disturbances increased along with the increasing doses of radiation (3.62\% to $41.68 \%$ ). Predominant abnormality observed during the study of all the 6 doses was stickiness or clumping (12.52\%) at Metaphase-I/II (Figs. 1E and J), multiva-

Fig. 1. A, Normal Metaphase-I ( $n=6)$, B, Normal Anaphase-I (6: 6 separation); C, Ring and Chain Multivalent formation at Metaphase-I; D, Secondary association at Metaphase-I; E, Stickiness at Metaphase-I; F. Precocious movement at Metaphase-I; G, Single bridge at Anaphase-I; H, Sticky bridge at Anaphase-I; I, Laggard at Anaphase-I; J, Stickiness at Metaphase-II; K, Single unoriented bridge at Anaphase-II; L, Non-synchronous division at Anaphase-II. 

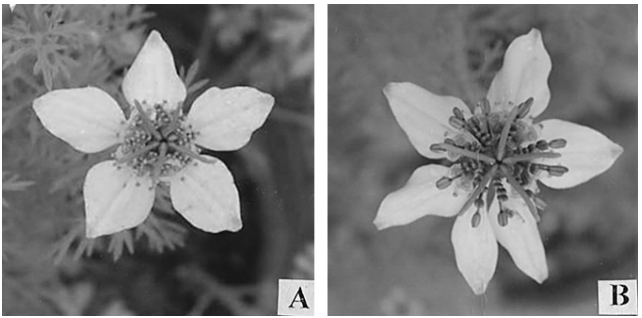

Fig. 2. A, Pentapetalous flower in control plants; B, Hexapetalous flower in mutant plant.
Table 3. Morphological parameters of hexapetalous mutant at 100 Gy dose of gamma rays.

\begin{tabular}{lcc}
\hline \hline Morphological parameter & Control & Mutant \\
\hline Plant height $(\mathrm{cm})$ & $54.86 \pm 0.86$ & $58.20 \pm 0.63$ \\
Stem Diameter $(\mathrm{cm})$ & $3.96 \pm 0.23$ & $4.2 \pm 0.46$ \\
No. of nodes & $15.4 \pm 0.23$ & $16.5 \pm 0.31$ \\
No. of petals & 5 & 6 \\
No. of seeds per capsule & 82 & 96 \\
100 seed weight $(\mathrm{gm})$ & $9.65 \pm 0.21$ & $9.72 \pm 0.67$ \\
Pollen fertility $(\%)$ & $98.0 \pm 0.34$ & $96.50 \pm 0.42$
\end{tabular}

lent (7.38\%) at metaphase-I (Fig. 1C). Other abnormalities frequently observed were precocious movement (Fig. 1F) and secondary association (Fig. 1D) at metaphase-I, lagging chromosomes at anaphase- I (Fig. 1I), single bridge at anaphase-I (Fig. 1G), sticky bridge at anaphase- I (Fig. H), unoriented single bridge at anaphase-II (Fig. 1K), non-synchronous division at anaphase/telophaseII (Fig. 1L) etc. Micronuclei and unorientation were however common at higher doses only (200-300 Gy). Studies on chiasma frequency revealed an increasing trend (4.5 \pm 0.2 at 50 Gy to $9.6 \pm 0.3$ at $300 \mathrm{~Gy})$ as compared to control (3.2 \pm 0.4$)$. This justifies the formation of multivalents at all the doses.

In addition to this, a hexapetalous mutant (Fig. 2B) was also observed at $100 \mathrm{~Gy}$ dose as compared to Pentapetalous flowers in control plants. (Fig. 2A). When the morphological parameters of the mutant and the control plants were compared (Table 3) it was found that the mutant plant had increased height $(58.20 \pm 0.63 \mathrm{~cm})$ as compared to control set $(54.86 \pm 0.45 \mathrm{~cm})$. Stem diameter of the mutant was found to be $4.2 \pm 0.46 \mathrm{~cm}$ as compared to $3.96 \pm 0.23 \mathrm{~cm}$ in control set. The mutant plant also had greater number of seeds i.e. 96 in comparison to control sets i.e. 82 . The 100 seed weight was recorded to be $9.72 \pm 0.67 \mathrm{gm}$ in the mutant plant as compared to the control set $(9.65 \pm 0.21 \mathrm{gm})$. However, the pollen fertility in the mutant plant was recorded to be $96.50 \pm 0.42 \%$ as compared to the control plants $(98.0 \pm 0.34 \%)$.

\section{Discussion}

The spectrum of chromosomal abnormalities induced by the gamma rays is broad and it includes a comparatively higher proportion of stickiness and multivalent. Stickiness has been reported to be a result of partial dissociation of nucleoproteins and alterations in the pattern of organization of chromosomes by Evans (1962) while Jayabalan and Rao (1987) attributed it to be due to the disturbances in cytochemically balanced reactions. However, it seems most probable that the gamma rays may have caused some kind of gene mutation, which leads to incorrect coding of some non-histone proteins involved in chromosome organization. When affected, these proteins lead to chromosome stickiness. Multivalent formation in the irradiated seed progenies has been attributed to the many breaks produced by gamma rays, which may lead to reciprocal translocation and resulting into multivalent formation. Such type of multivalent formation has also been reported in irradiated plants of rice (Radha Devi and Reddi 1997).

Chromosome bridges may arise due to stickiness or due to the formation of dicentric chromosome by breakage and reunion. Secondary association of chromosomes, in many diploid species, has been interpreted as a result of modified chromosome rearrangement due to duplication, interchanges or stickiness. Other abnormalities like precocious movement, laggard, non-synchronous division and unorientation may appear because of abnormal spindle activity (Kumar and Singh 2003). Laggards and non-oriented bivalents may produce micronuclei if they fail to reach the poles in time 
to be included in the main nucleus (Koduru and Rao 1981)

As more and more abnormalities accumulate the process of gamete formation is affected and it leads to non-viable gametes that considerably reduce the plant fertility, which is clearly visible in the present study since pollen fertility registered a marked decrease after the gamma rays treatment. Studies on different plant species have shown that the decline in seed production is correlated with the meiotic irregularities (Pagliarini and Periera 1992, Pagliarini et al. 1993, Consolaro et al. 1996, Khazanderi and Jones 1997).

From the foregoing study it can be concluded that mutation/variation can possibly be created through the gamma rays. But specific effective dose varies from plant to plant. In Nigella sativa 100 Gy dose seems to be most effective since it produces hexapetalous flowers with better yield (increased number of seeds and seed weight) and also the abnormality percentage at this dose is $17.10 \%$ as compared to $41.68 \%$ at $300 \mathrm{~Gy}$ dose. This is an optimum level of abnormality, which will not produce any deleterious effect on the chromosome complement of the plant. Thus it can be suggested that various traits can be improved upon in desired plants even at lower doses of gamma rays.

\section{Acknowledgements}

One of the authors (P.G) is thankful to UGC for the financial assistance in the form of JRF. Thanks are also due to CSA, Kanpur for providing the seeds.

\section{References}

Ahmad, S. 1993. Meiotic Studies in two cultivars of Cicer arietinum L. after gamma irradiation. Cytologia. 58: 61-65.

Alvarez, E., Alonso-Blanco, C., Suarez, R. G., J.J Roca, A. and Giraldez, R. 1997. A strategy for detecting chromosome specific rearrangements in rye. Genome. 40: 451-457.

Bhattacharya, N. K .1958. Cytology of two species of Nigella. Genet. Iber. 10: 179-190.

Biswas, A. K. and Bhattacharya, N. K. 1975. Effect of some radiometric chemicals on plant chromosomes. Science and Culture. 41: 129-130.

Consolaro, M. E. L., Pagliarini, M. S. and Chaves, L. J. 1996. Meiotic behaviour, pollen fertility and seed production in Brazilian populations of (L.) Urban (Umbelliferae). Cytologia 61: 375-381.

Epstein, S. S. and Legator, M. 1971. The mutagenicity of pesticides. MIT Press, MA, U.S.A.

Evans, H. J. 1962. Chromosome aberrations induced by ionizing radiations. Int. Rev. Cytol. 13: 221-232.

Gecheff, K. I. 1996. Production and Identification of new structural chromosome mutations in Barley (Hordeum vulgare). Theor. Appl. Genet 92: 777-781.

Jayabalan, N. and Rao, G. R 1987. Gamma radiation induced cytological abnormalities in Lycopersicon esculentum Mill var Pusa Ruby. Cytologia. 52: 1-4.

Khazanehdari, K. A. and Jones, G. H. 1997. The causes and consequences of meiotic irregularity in the leek (Allium ampeloprasum spp. Porrum) implications for fertility, quality and uniformity. Euphytica 93: 313-319.

Koduru, P. R. K. and Rao, M. K. 1981. Cytogenetics of synaptic mutants in higher plants. Theor Appl Genet. 59: $197-214$.

Kumar, G. and Singh, V. 2003. Comparative analysis of meiotic abnormalities induced by gamma rays and EMS in Barley. J. Ind. Bot. Soc. 82: 19-22.

— and Rai, P. 2007. Comparative Genotoxic Potential of Mercury and Cadmium in Soybean. Turk. J. Biol. 31: $13-18$.

Kumar, P. and Nizam, J. 1978. Effect of X-rays on Nigella sativa. 3rd All India Congress of Cytology and Genetics (abst) p. 7.

Pagliarini, M. S. and Pereira, M. A. S. 1992. Meiotic studies in Pilocarpus pennatifolius Lem. (Rutaceae). Cytologia 57: 231-235.

—, Pissinatti, M. B. and Silva, N. 1993. Chromosomal behaviour and seed production in Chlorophytum comosum (Liliaceae). Cytologia 58: 433-437.

Pruthi, J. S. 1998. Spices and Condiments. National Book Trust, India. pp. 118-120.

Radhadevi, K. and Reddi, T. V. V. 1997. Cytogenetics of interchange heterozygotes in scented rice by recurrent treatments with gamma rays. J. Cytol. Genet 32: 129-133.

Riera-Lizarazu, O., Vales, M. I., Ananiev, E. V., Rines, H. W. and Philips, R. L. 2000. Production and characterization of maize chromosome 9 radiation hybrids derived from oat-maize addition line. Genetics 156: 327-339. 
Stebbins, G. L. 1950. Variation and evolution in plants. New York: Columbia University Press.

Vizir, I. Y., Anderson, M. L., Wilson, Z. A. and Mulligan, B. J. 1994. Isolation of deficiencies in the Arabidopsis genome by g-irradiation of pollen. Genetics 137: 1111-1119. 